\title{
Carbon Break Even Analysis: Environmental Impact of Tablets in Higher Education
}

\author{
Fadi Safieddine \\ College of Business \\ The American University of the Middle East, \\ Kuwait
}

\author{
Imad Nakhoul \\ College of Business \\ The American University of the Middle East, \\ Kuwait
}

\begin{abstract}
With the growing pace of tablets use and the large focus it is attracting especially in higher education, this paper looks at an important aspect of tablets; their carbon footprint. Studies have suggested that tablets have positive impact on the environment; especially since tablets use less energy than laptops or desktops. Recent manufacturers' reports on the carbon footprint of tablets have revealed that a significant portion, as much as $80 \%$, of the carbon footprint of tablets comes from production and delivery as opposed to the operational life-cycle of these devices. Thus rending some of previous assumptions about the environmental impact of tablets questionable. This study sets to answer a key question: What is the break-even analysis point when saving on printed paper offsets the carbon footprint of producing and running the tablet in higher education. A review of the literature indicated several examples of tablet models and their carbon emission impact; this is compared to the environmental savings on paper that green courses could produce. The analysis of the carbon break-even point shows that even when considering some of the most efficient and least carbon impact tablets available on the market with a carbon-footprint production of $153 \mathrm{Kg} \mathrm{CO} \mathrm{CO}_{2} \mathrm{e}$, the breakeven point is 81.5 months; referring to 6 years, 9 months and 15 days of use. This exceeds the life-cycle of an average tablet of five years and average degree duration of four years. While tablets still have the least carbon-footprint impact compared to laptops and desktops, to achieve the break-even point of carbon neutral operations this study concludes that manufacturers need to find more environmentally efficient ways of production that would reduce the carbon-footprint product to a level that does not exceed 112.8kg $\mathrm{CO}_{2} \mathrm{e}$.
\end{abstract}

Keywords-Environmental, Tablet; Higher Education; Carbonfootprint; Break-even Analysis

\section{INTRODUCTION}

The tablet industry is comparable to the mobile device industry in its growing pace and in its increased usage. Tablets are becoming a part of higher education delivery approach and is considered to turn into habitually usage in higher education replacing the longstanding method of course delivery: papers.

While the demand is growing and many advantages highlighted in previous publications about the usage of tablets in higher education [1], assumptions are made regarding the environmental impact of tablets and specifically their impact in reducing energy use and reducing paper usage.

In this paper, the team have set out to design a framework to better evaluate the environmental impact of tablets or computing devices in higher education thus setting the bar for future computing devices environmental impact studies. When justifying a technology as reducing environmental impact, the team suggest to look at the carbon foot print of the production and overtime use of such devices, compare it to the reduction in emission it help reduce, while considering the average lifecycle of these devices to appreciate the net impact. In doing so, the team conducted a literature review collecting valuable information that helped identify the breakeven point for tablets.

\section{LITERATURE REVIEW}

\section{A. Tablets and higher education:}

There are significant evidence in the literature regarding the positive financial impact for organizations to go paperless in their operations [1], [2], [3], \& [4]. There are also several publication on how academics have been successful in going paperless in higher education [5-9]. One of the key aspects that have helped fan the move to paperless classrooms or totally green courses is the use of Virtual Learning Environment (VLE). In fact, three studies have reviewed the impact of switching courses from paper based to complete paperless on students' performance and in both cases the results have been favorable [10], [11], \& [12].

The use of tablets in higher education has also been subject of several studies. A survey of higher education libraries in the U.S. has shown an increase use and dependency on educational technologies such as tablets [13]. In two separate studies, researchers have been able to prove that learning from electronic tablet screens does not affect the efficiency of learning compared to printed publications [14], [15]. In one of the largest study conducted on the use of tablets in higher education involving a sample of 280 students from several universities, researchers suggested the use of tablet promoted an active-learning environment with positive learning experiences from across the board [16]. In fact, increasingly more research into tablets in higher education is showing high acceptability rate [17 - 19], learners increase dependency on M-learning [20] \& [21], and successful implementations of such devices [16] \& [22]. Portability, mobility, and the longer battery are suggested as key success factor of tablets [18].

The underlining perception for many of the studies is that encouraging the use of tablets in higher education has positive environmental impact [1], [10], [13], [23], \& [24]. And while 
this may well be the case when compared to other computing devices, the real data on this is still rather missing.

\section{B. Environmental Impact of tablets}

An independent research think-tank [25] suggested in 2012 that tablets produce less carbon emissions during their production and operation lifecycle compared to desktops and laptops. The study focused on a review of Apple Product Environmental Report [26]. In comparing the production footprint of two iPad tablets, two Mac laptops, and two Mac desktops, the research think-tank concluded that Apple iPad tablets carbon footprints are usually less than $10 \%$ compared to a Mac Pro Desktop while iPad tablets carbon footprint stood less than $30 \%$ of that of the average Mac laptop. The results looked further in favor of tablets when looking at the operational impact. A 10,000 hours average use of each device comparison showed that the average iPad tablets used as little as $1 \%$ electricity when compared to a Mac desktops and between 3 to $30 \%$ of that of comparable Mac laptops At least in the case of the Apple devices, the results seem to be conclusively in favor for a move to tablets as oppose to any other device.

Apple Inc. provides an interesting analysis that sheds light to the main source of emissions in the lifetime of a tablet. According to the Environmental Report for iPad Air 2 [27] the total carbon emission of the tablet in its lifetime is estimated to be $170 \mathrm{Kg} \mathrm{CO}_{2} \mathrm{e}$ in greenhouse gas emissions. However, the customer usage only amounts to $10 \%$ of that figure. $86 \%$ of the carbon emissions of an iPad Air 2 comes from the production of the tablet itself see Fig. 1.

The breakdown of carbon emission for the tablet is shown in Table 1.

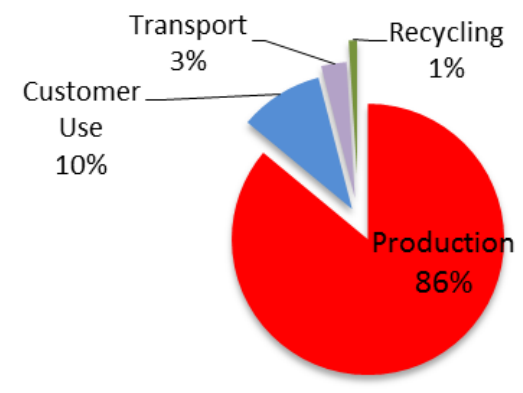

Fig. 1. Greenhouse Gas Emissions for iPad 2 (Wi-Fi + Cellular) [28]

TABLE I. BREAKDOWN OF THE CARBON-EMISSION

\begin{tabular}{|c|c|c|}
\hline iPad Air2 & Percentage & $170 \mathrm{~kg} \mathrm{CO}_{2} \mathrm{e}$ \\
\hline Production & $86 \%$ & $146.2 \mathrm{~kg} \mathrm{CO}_{2} \mathrm{e}$ \\
\hline Customer Use & $10 \%$ & $14.62 \mathrm{~kg} \mathrm{CO}_{2} \mathrm{e}$ \\
\hline Transport & $3 \%$ & $0.4386 \mathrm{~kg} \mathrm{CO}_{2} \mathrm{e}$ \\
\hline Recycling & $1 \%$ & $0.004386 \mathrm{~kg} \mathrm{CO} 2 \mathrm{e}$ \\
\hline
\end{tabular}

While the European Union Energy Efficiency Star rating of electronic products has focused on the energy usage during operation of a device [28], the literature review regarding tablets suggests that the rating of tablets' environmental impact purely on operational usage is misleading consumers.
Of course not all tablets rate the same. An internal comparative study of different means of studying by Wageningen UR University in the Netherlands reviewed several tablets available on the market and their environmental impact as opposed to buying books [29]. The study looked specifically at students' use and higher education. The study concludes that tablets rate better at environmental impact when compared to laptops and significantly better when compared to desktops.

The only other comparative study the team was able to find is that of an Australian independent consumer services [30]. In their consumer report, the authors suggests that Apple iPad do rate the highest for energy efficiency and lowest in carbon footprint while Toshiba and Google tablets ranked the least efficient. However, no data was provided that would justify the rating or ranking of these tablets. The ranking is not linked to specific tablets. What is more, the ranking doesn't focus merely on the environment impact, it mixes environmental and social impacts.

\section{Paper Use in Higher Education}

There is limited literature on the use of paper in higher education. The team will be relying in this instance on a study conducted at University of East London between 2006 and 2013 as the authors recorded the switch from paper based to completely Green courses [10]. In a follow up study, the team looked at specific use of paper, paper printing, and books part of cost-benefit analysis for running Green courses and their impact on the university, students, and faculty [1]. The following is an extract of that data quantifying the average use of papers per students for every course in each semester that the team will abbreviate as APUSCS (Average Paper Used per Student per Course per Semester).

$$
\begin{aligned}
& \text { University: } \\
& \text { - } \quad \text { Course Syllabus/Handbook: } 37 \text { APUsCs } \\
& \text { - } \quad \text { Handouts: } 24 \text { APuscs } \\
& \text { - Exam \& Quizzes: } 28 \text { APUSCS } \\
& \text { Student: }
\end{aligned}
$$

- $\quad$ Course work printing: 137.5 APUSCS

- Course book: One textbook per course and semester.

The total paper saving is 226.5 pages plus one textbook per student, per course, per semester.

\section{Environmental Impact of Printed Papers}

In the case of course books, the team have found one study by the US government Environmental Protection Agency department that suggested the carbon emission of printing an average textbook to be $2.4 \mathrm{~kg} \mathrm{CO}_{2} \mathrm{e}$ [31]. And since almost all courses require one core textbook, the team have assumed the carbon-emission to be $2.4 \mathrm{~kg} \mathrm{CO}_{2} \mathrm{e}$ per course. The same report looked at the environmental impact of using and printing papers with the study suggesting that 100 pages of papers generate $1.26 \mathrm{~kg} \mathrm{CO}_{2} \mathrm{e}$. This number has been cross checked with another two studies in which the team reached very similar figures of $1.251 \mathrm{~kg} \mathrm{CO}_{2} \mathrm{e}$ for 100 printed papers [32] and consistent with another study in which carbon emission of 100 plain papers are calculated to be around $0.938 \mathrm{Kg} \mathrm{CO}_{2} \mathrm{e}$ [33]. 


\section{RESEARCH QUESTIONS AND METHODOLOGY}

\section{A. Research Questions:}

The team set out to determine a key fact when it comes to evaluating the real environmental impact of tablets and to do so the team aimed to answer these questions:

1) What is the breakeven point when the use of a tablet becomes carbon neutral in Higher Education?

2) What is the carbon-emission target that companies need to aim at when designing greener tablets for higher education institutions?

\section{B. Methodology:}

From the literature review, the team has been able to determine the importance of tablets in the future of academia. The team has also been able to determine key details about the carbon-emission based on some key facts published by renounced manufacturers. Two important and distinctive variables have been identified: fixed carbon-emission of tablets representing the manufacturing, delivery, and recycling carbon footprint; and variable carbon-emission of tablets representing the impact of running the tablet. Unfortunately, there is one company who has provided those two details. Thus the team has decided to use the Apple iPad 2 carbonemission data after careful consideration of the characteristics of that tablet. The tablet represents a well-known brand with some evidence of it being an energy efficient device.

On the other hand, the team has also been able to determine reasonable value to consider as average use of papers by students per course per semester. Finally, the team has been able to determine the carbon emission that would be fair means to judge the carbon impact of paper printing in academia. The printing of paper is a running variable that would in theory continue until a carbon neutrality impact is achieved. However, there will one important factor that the team will consider and is represented in the fact that an average tablet has a technological life-cycle that is unlikely to exceed five years. The aggregation of all these facts, fixed and variable carbon emission impact from tablets against the carbon emission saving from not printing are plotted on the break-even analysis diagram to determine the breakeven point in months. This would answer research question 1 and 2 . Where the diagram exceeds the five-year life cycle of tablets, the team will perform breakeven sensitivity point analysis to determine what target should be for manufacturers of tablets in developing greener tablets.

\section{RESULTS AND ANALYSIS}

Case 1: Based on the literature review findings, the team has calculated the breakeven analysis where four factors have been considered:

Fixed Carbon-emission of a tablet for the manufacturing, delivery, and recycling to be $153 \mathrm{~kg} \mathrm{CO}_{2} \mathrm{e}$.Variable Carbonemission of the tablet to be $17 \mathrm{~kg}$ over 5 years or $0.2833 \mathrm{~kg}$ $\mathrm{CO}_{2} \mathrm{e}$ per month.

Fixed Carbon-saving from papers per student: 0kg since all the savings are variable.
Variable Carbon-saving from papers per student per course per semester to be: 226.5 papers or $2.85 \mathrm{~kg} \mathrm{CO}_{2} \mathrm{e}$. This is added to $2.4 \mathrm{~kg}$ for each textbook bringing the total to: 5.2539 $\mathrm{kg} \mathrm{CO}_{2} \mathrm{e}$ per course per semester. Student take on average three course for two semester, so the total annual running carbon saving is $5.2439 \times 3$ course $\times 2$ semester to be $31.5234 \mathrm{~kg} \mathrm{CO} 2$ e. Divided over 12 -month period, the variable Carbon-saving from per student per month is $2.62695 \mathrm{~kg} \mathrm{CO}_{2} \mathrm{e}$.

When plotting these results onto a breakeven analysis diagram, the results show a breakeven point in 81.5 months, or in other words 6 years, 9 months and half. This is shown in Fig. 2.

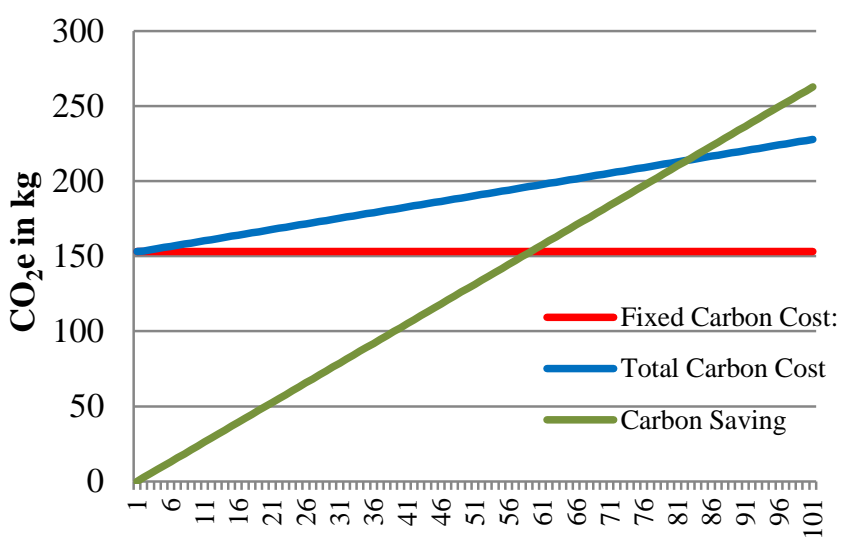

Time in Months

Fig. 2. Breakeven analysis for Case 1

This breakeven point exceeds the life cycle of the tablet and exceeds the length of most degree programmes, which is four years in the UK.

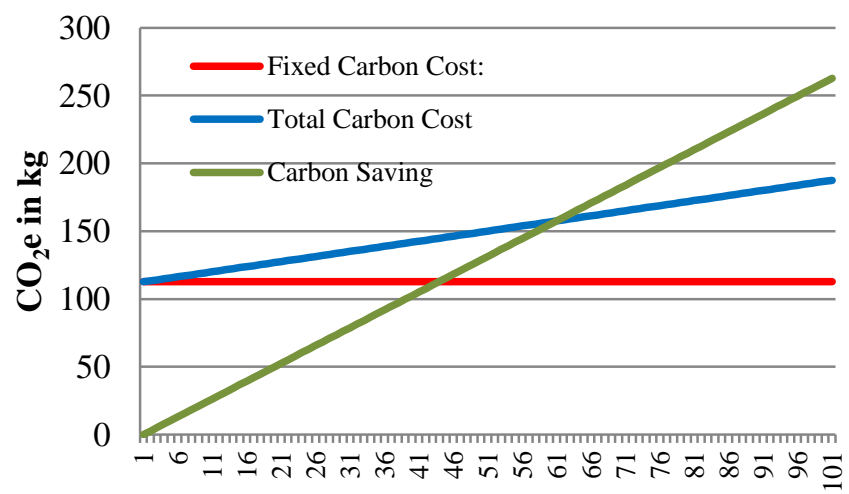

Time in Months

Fig. 3. Breakeven sensitivity analysis for Case 2

Case 2: The team then looked at the breakeven sensitivity analysis to determine what manufacturers and academics need to consider when looking for greener and carbon-neutral tablets and to achieve the life-cycle of five years for a tablet, considering in this case the production lines could be made to run more efficiently. The results showed that manufacturers need to produce, deliver, and recycle tablets at a rate that does 
not exceed $112.8 \mathrm{~kg} \mathrm{CO}_{2} \mathrm{e}$ in which the new breakeven point would be in year 5 at $158 \mathrm{~kg} \mathrm{CO}_{2}$ e see Fig. 3 .

The evidence shows conclusively that the largest contribution to greenhouse gases is the production of the tablet. The same could be said regarding other devices. In academic environment where paper usage is considered high, the tablet failed to break-even in a considerable time. For tablets to be considered a product of neutral or positive impact on the environment, manufacturers need to consider several factors that could help achieve a greener status for higher education institution. For production, manufacturers would need to consider ways to reduce energy use, relying more on renewable energy sources. The supply chain network involved in the production of the material for the production of these tablets could be another area that could be optimized. Finally transport of these devices to the consumers

\section{RESEARCH LIMITATIONS}

Ascertaining what the carbon-footprint for an average tablet proved to be illusive, mainly because manufacturers are not required to provide this information. Instead the focus is on the energy usage during the operation of tablets. The team determination to select one model as an example is a research limitation and where possible the carbon-emission breakeven analysis could be applied for different tablet models.

Another concern comes from the fact that there are no academic publications on the actual carbon-footprint for the production of papers. Moreover, on the carbon-footprint of printed papers the team resorted to reviewing variety of figures from governmental and environmental agencies to reach a number that the team has confidence in being representative of the actual carbon-footprint of printed papers.

Finally, the study looks at only one aspect of the carbon saving a tablet can produce and that is for papers. There may be other aspects of saving on transportation where tablets can reduce transport of paper, books, and travel. Tablets could also contribute to reduction in use and need for labs in higher education; where students replace use of desktop computers for more energy efficient tablets. This may contribute to reducing investment by higher education institutions in ICT labs.

Despite these limitations, the team is confident that the data presented regarding the tablet carbon-footprint and paper saving footprint are reasonable. And while there may well be other factors that could be considered in the carbon saving associated with use of tablets, paper saving will remain the most significant and until further research reveals otherwise.

\section{CONCLUSION}

Evidently, manufacturers have focused far and long on getting more energy efficient electronics to meet the demands of consumers seeking to reduce their energy bills. The running carbon-footprint of tablets could be seen as evidence of this trend. The focus could now be shifted towards the production and supply chain process as source of providing truly greener products.
More is needed to learn about the carbon-footprint of other computing devices. The industry should be seeking to not only produce products that reduce their running carbon-footprint but that surpasses in their life-cycle the carbon-footprint generated from their production. This study could be replicated as new devices are produced and new data is provided regarding these products carbon-footprint. This study could be replicated for other service and manufacturing organizations looking to reduce their carbon footprint. Presenting the carbon-footprint of a products as merely the running carbon footprint should be deemed as misleading consumers. Governments and energy rating agencies around the world need to enforce and enhance such criteria to allow better comparison of products by consumers.

\section{REFERENCES}

[1] I. Nakhoul, and F. Safieddine, "Quantitative cost-benefit analysis of green courses: case study," International Technology, Education and Development Conference Proceedings, Valencia, Spain, 2014, pp. 34763482

[2] J.T. Ryan, "Document-management systems offer efficiency, save paper," Central Penn Business Journal, 2008, Vol 1(2).

[3] T. Thompson, "Less paper trumps paperless," Health Management Technology, 2008, pp. 42-43.

[4] F. M. Jurgens, "The paperless classroom goes to sea," Sea Power, 2000, Vol 43(2). Retrieved November 2, 2008 from ProQuest: ISSN 01991337.

[5] J. Slowinski, "Flaunt IT: Construction of a Paperless Classroom," in L. Mealy and B. Loller (eds) e-learning: Expanding the Training Classroom through Technology, 2000, pp. 117-127.

[6] A. Rea, D. White, R. McHaney, and C. Sanchez, "Pedagogical Methodology in Virtual Courses," in A. Aggarwal (ed.) Web-based learning and teaching technologies: opportunities and challenges, 2000, pp. 138-139.

[7] K. D. Lutes, and A. Harriger, "Essignments - A step toward the paperless classroom," Hawaii International Conference on Education, 2003.

[8] B. Meyer, "The Process of Implementing a Paperless Classroom in Teacher Education Using an Electronic Portfolio System. MountainRise," the International Journal of the Scholarship of Teaching and Learning, 2008.

[9] J. Arney, I. Jones, and A. Wolf, "Going green: paperless technology and feedback from the classroom," Journal of Sustainability and Green Business, 2010.

[10] F. Safieddine, and S. Wee Lee, "Green modules for sustainability in higher education: A longitude study on impact on students," International Technology, Education and Development Conference Proceedings. Valencia, Spain, 2013.

[11] J. Fei Wang, "Creating a Paperless Classroom with the Best of Two Worlds," Journal of Instructional Pedagogies. 2, 2010.

[12] S. De Bonis, and N. De Bonis, "Going Green: Managing a Paperless Classroom," US-China Education Review A 1 , 2011, 83-87. ISSN 1548-6613

[13] E. D. Cassidy, A. Colmenares, G. Jones, T. Manolovitz, L. Shen, and S. Vieira, "Higher Education and Emerging Technologies: Shifting Trends in Student Usage, ” Journal of Academic Librarianship, Mar 2014, Vol. 40 Issue 2, p124-133.

[14] L. Bayliss, C. Connel, and W. Farmer, "Effects of ebook readers and tablet computers on reading comprehension," Journal of Instructional Media, 2012, Vol 39(2), pp. 131-140.

[15] H. Dundar, and M. Akcayir, "Tablet vs. paper: The effect on learners' reading performance," International Electronic Journal of Elementary Education, 2012, Vol 4(3), pp. 441-450.

[16] M. Stickel, S. Edward, and Sr. Rogers, "Impact of lecturing with the tablet PC on students of different learning styles," Frontiers in Education Conference, 2009, FIE '09. 39th IEEE. pp. $1-6$. 
[17] T.J. Perez Decano, "Willingness of students to use tablets as a learning tool," Educational Media (ICEM), IEEE 63rd Annual Conference International Council for Education and Media, 2013, pp.1-9.

[18] E.M. Maina, R.W. Njoroge, P.W. Waiganjo, and R. Gitonga, "Use of tablets in blended learning: A case study of an Institution of Higher Learning in Kenya," IST-Africa Conference 2015 Proceedings, 2015, pp. 1-8.

[19] M. Moran, M. Hawkes, and O. Gayar, "Tablet Personal Computer Integration in Higher Education: Applying the Unified Theory of Acceptance and Use Technology Model to Understand Supporting Factors," Journal of Educational Computing Research, 2010, Vol. 42(1) p.p.79-101.

[20] Y. Park, "A pedagogical framework for mobile learning: Categorizing educational applications of mobile technologies into four types," The International Review of Research in Open and Distributed Learning. 2011, Vol 12.2. pp. 78-102.

[21] M. Sharples, J. Taylor, and G. Vavolva, "A Theory of Learning for the Mobile Age," Medienbildung in neuen Kulturräumen, 2007, pp 87-99

[22] J.C. Santamartaa, L.E. Hernández-Gutiérrezb, R. Tomásc, M. Canoc, J. Rodríguez-Martínd, and M.P. Arraizae, "Use of Tablet Pcs in Higher Education: A new Strategy for Training Engineers in European Bachelors and Masters Programs." Procedia - Social and Behavioral Sciences, 2 June 2015, Vol(191), p.p 2753-2757

[23] J. Arney, I. Jones, and A. Wolf, "Going green: paperless technology and feedback from the classroom," Journal of Sustainability and Green Business, 2010.

[24] S. De Bonis, and N. De Bonis, "Going Green: Managing a Paperless Classroom," US-China Education Review, 2011, Vol 1, 83-87. ISSN $1548-6613$

[25] L. Wilson, "iPad or book? Is it time to go tablet for the planet?" Shrink
Think-Tank, 2012, Last accessed (March 26th 2016) at http://shrinkthatfootprint.com/ipad-mini

[26] Apple Inc. "Product Report: Measuring Performance One Product at a Time," n.d., Last accessed (March, 26 ${ }^{\text {th }}$ 2016) at http://www.apple.com/environment/reports/

[27] Apple Inc. "iPad Air 2. Environmental Report," 2016, Last accessed (March 26, 2016) at http://images.apple.com/environment/pdf/products/ipad/iPadAir2_PER_ oct2014.pdf

[28] EU Energy Star. "Energy Calculator for PC Equipment.”, 2016, Last accessed (26 ${ }^{\text {th }}$ March 2016). https://www.eu-energystar.org/

[29] Green Office Wageningen. "CO2 footprints of Kindle vs iPad vs Books," Wageningen UR University Internal Press, 2014, Last accessed (March 26th 2016) https://gowageningen.files.wordpress.com/2014/04/co2-footprints-ofkindle-vs-ipad-vs-books.pdf

[30] Choice. "Why every tablet has a footprint: Tablet manufacturers' environmental and social policies compared," n.d., Last access (March 26, 2016) at https://www.choice.com.au/electronics-andtechnology/tablets-and-personal-media-devices/tablets/articles/tabletenvironmental-footprint-report

[31] US Environmental Protection Agency. "Solid Waste Management and Greenhouse Gases A Life-Cycle Assessment of Emissions and Sinks3rd edition," 2006, Chapter 2. Column g. p. 24.

[32] Environmental Paper Network (EPN). "Lifecycle Environmental Impact: Online Calculator," 2014, Last accessed 25th of April 2016 at http://c.environmentalpaper.org/baseline

[33] S.S. Muthu, "The Carbon Footprint Handbook," 2015, CRC Press. London. p.497. 